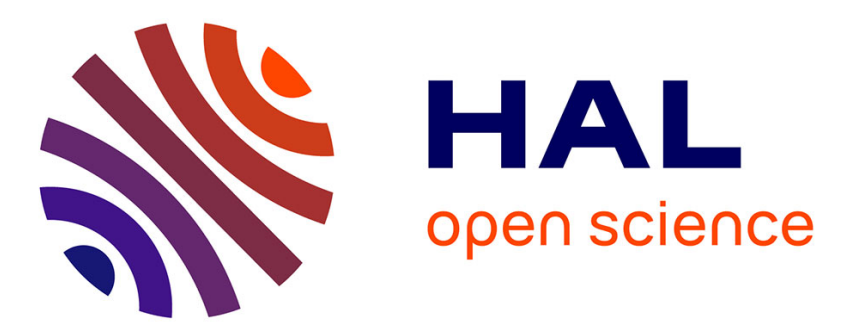

\title{
Adsorption Mechanisms of Emerging Micro-pollutants with a clay Mineral: Case of Tramadol and Doxepine Pharmaceutical Products
}

Thomas Thiebault, Régis Guégan, Mohammed Boussafir

\section{- To cite this version:}

Thomas Thiebault, Régis Guégan, Mohammed Boussafir. Adsorption Mechanisms of Emerging Micropollutants with a clay Mineral: Case of Tramadol and Doxepine Pharmaceutical Products. Journal of Colloid and Interface Science, 2015, 453, pp.1-8. 10.1016/j.jcis.2015.04.029 . insu-01163181

\section{HAL Id: insu-01163181 https://hal-insu.archives-ouvertes.fr/insu-01163181}

Submitted on 12 Jun 2015

HAL is a multi-disciplinary open access archive for the deposit and dissemination of scientific research documents, whether they are published or not. The documents may come from teaching and research institutions in France or abroad, or from public or private research centers.
L'archive ouverte pluridisciplinaire $\mathbf{H A L}$, est destinée au dépôt et à la diffusion de documents scientifiques de niveau recherche, publiés ou non, émanant des établissements d'enseignement et de recherche français ou étrangers, des laboratoires publics ou privés. 


\section{Accepted Manuscript}

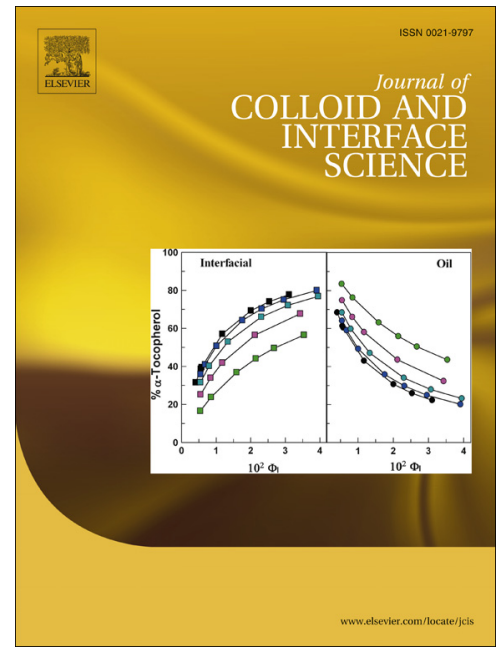

Adsorption Mechanisms of Emerging Micro-pollutants with a clay Mineral:

Case of Tramadol and Doxepine Pharmaceutical Products

Thomas Thiebault, Régis Guégan, Mohammed Boussafir

PII:

S0021-9797(15)00399-9

DOI:

http://dx.doi.org/10.1016/j.jcis.2015.04.029

Reference:

YJCIS 20409

To appear in:

Journal of Colloid and Interface Science

Received Date: $\quad 2$ March 2015

Accepted Date: $\quad 12$ April 2015

Please cite this article as: T. Thiebault, R. Guégan, M. Boussafir, Adsorption Mechanisms of Emerging Micropollutants with a clay Mineral: Case of Tramadol and Doxepine Pharmaceutical Products, Journal of Colloid and Interface Science (2015), doi: http://dx.doi.org/10.1016/j.jcis.2015.04.029

This is a PDF file of an unedited manuscript that has been accepted for publication. As a service to our customers we are providing this early version of the manuscript. The manuscript will undergo copyediting, typesetting, and review of the resulting proof before it is published in its final form. Please note that during the production process errors may be discovered which could affect the content, and all legal disclaimers that apply to the journal pertain. 


\title{
Adsorption Mechanisms of Emerging Micro-pollutants with a clay Mineral: Case of Tramadol and Doxepine Pharmaceutical Products
}

\author{
Thomas Thiebault, Régis Guégan", Mohammed Boussafir
}

Institut des Sciences de la Terre d'Orléans, UMR 7327, CNRS-Université d'Orléans, 1A Rue de la Férollerie, 45071 Orléans Cedex 2, France

thomas.thiebault@cnrs-orleans.fr

regis.guegan@univ-orleans.fr

mohammed.boussafir@univ-orleans.fr

\section{April 07 ${ }^{\text {th }}, 2015$}

*To whom correspondence should be addressed. E-mail: regis.guegan@univ-orleans.fr. Phone: +33 (0) 2384925 41. Fax: +33 (0) 238636488

\begin{abstract}
A sodium exchanged smectite clay mineral (Mt) was used as geo-sorbent for the adsorption of tramadol and doxepin: two pharmaceutical products (PPs) defined as emerging pollutants due to their presence at significant concentration in numerous water compartments. The adsorption isotherms for both the temperatures of 20 and $40^{\circ} \mathrm{C}$ and the derived data determined through the fitting procedure by using Langmuir, Freundlich and Dubinin-Radushkevich equation models explicitly pointed out that the sorption of both tramadol and doxepin is mainly driven by electrostatic interaction. The studied PPs are intercalated in a monolayer arrangement within the interlayer space through a cation exchange in stoichiometric proportion with the $\mathrm{Na}^{+}$cations leading to adsorbed PPs amounts that match the cation exchange capacity (CEC) of Mt. Due to their hydrophobic character, additional doxepin molecules could be adsorbed by weak molecular interaction driving to an increase of the adsorbed amount beyond the CEC at low temperature $\left(20^{\circ} \mathrm{C}\right)$. The confinement of PPs within the interlayer space of Mt confirms the use of clay minerals as potential material for the wastewater treatment as well as it drives to an amorphous or glassy state, which can find echo in biopharmaceutical applications for a controlled release of PPs.
\end{abstract}




\section{Introduction}

The massive and frequent consumption of more than 3000 pharmaceutical products (PPs) in modern developed countries causes environmental issues on numerous ecosystems [1-9]. Indeed, the occurrence of these pharmaceutical active compounds classified as emerging micro-pollutants in several aquatic compartments, were detected at concentrations up to the microgram per liter, through the recent development of analytical methods such as gas chromatography $[1,2,10]$. Addictive and psychoactive drugs, such as tramadol, doxepin and other derivatives as well as illicit drugs (cocaine, heroin) lead to serious issue even at low concentration due to their low degradation, significant side effects (anxiety, dementia, paranoia) and possible addictions to drugs [10-12]. Tramadol, a central analgesic of which therapeutic action occurs on the morphine receiver as a pain control, is extensively used after surgical operations or chronic diseases whereas Doxepin, a tricyclic antidepressant with a tertiary amine group, is prescribed against depression and anxiety. Despite their restricted uses, tramadol was identified at high concentration $\left(0.2 \mu \mathrm{g} . \mathrm{L}^{-1}\right)$ in numerous water compartments due to its chemical stability and low biodegradability as well as to the deficiency of traditional waste treatment.

Adsorption is the most appropriate easy way to remove both inorganic and organic micro-pollutants. The selected adsorbents must show a large specific surface area and excellent affinity to micropollutants. Among natural materials, activated carbon, clay minerals, zeolites are commonly used for the treatment of water. Activated carbon exhibits excellent adsorption properties for many organic products; nevertheless its use is rather limited due to its expensive cost [7, 13-15]. Adsorption properties of clay minerals and their organoclay derivatives are known for many years and used in numerous applications as reinforcements in composite materials, geochemical barriers in waste landfills or filters in water treatment plants [16-20]. These layered materials show non-singular hydration properties with a macroscopic swelling, a cation exchange capacity (CEC) allowing the intercalation of micro-pollutants within the interlayer space. Moreover, these environmental friendly materials are commonly used in the pharmaceutical industry as excipients or active substances [14,21]. 


\section{ACCEPTED MANUSCRIPT}

This study aims to characterize the adsorption of both the tramadol and doxepin and to highlight their affinity with a clay mineral. If clay mineral and activated charcoal in vivo conditions were used as adsorbent for tramadol release systems [21, 22], no study focuses on the efficiency of the sorbent material for the remediation of both tramadol and doxepin nor the identification of the interactional mechanisms involved between these PPs and clay mineral surface. The selection of these pharmaceutical compounds is justified in regards to their occurrence and concentration for tramadol while doxepin seems to be not retained despite the different wastewater treatment stages $[1,2,12]$. Thus, in order to emphasize the main interactional processes involved in the adsorption of these PPs onto a clay mineral (a reference sodium exchanged smectite), the sorption study was performed on a wide range of concentration beyond the measured concentration in wastewater and for both the temperatures of 20 and $40^{\circ} \mathrm{C}$. In that way, the resulting experimental adsorption isotherms could be properly fitted by standard Langmuir, Freundlich, and Dubinin-Radushkevich equation models allowing one to quantify precisely the affinity of both PPs with clay mineral and to highlight the main driving force for the adsorption, which is rather difficult to obtain if one restricts its adsorption study in low concentration regime (i.e. $\left.<1 \mu \mathrm{g} \cdot \mathrm{L}^{-1}\right)$. We assumed our experimental data obtained in high concentration and the determination of the main interactional processes of PPs with clay mineral may be easily adapted in low concentration regime, the opposite may nevertheless not be valid. Beyond the environmental interest, the adsorption of PPs into layered materials generates pharmaceutical composites with a controlled drug release avoiding fluctuations neither any excess in plasmatic levels, which occur frequently through conventional drug release forms. Amorphous PPs forms display preferential pharmacokinetic properties in contrast to thermodynamically stable crystalline PPs [23]. In addition to reduce the PPs concentration for an equivalent therapeutic action and as a result a diminution of their release in the environment, the confinement into the interlayer space of clay minerals may affect both dynamics and structure $[21,24]$. The intercalated organic species show a non-singular bulk-like behavior with amorphous structures and a heterogeneous dynamics [25-28]. The study of adsorption PPs 
onto clay minerals and their conformation and structure may contribute to a better understanding of the efficiency of the drug release.

\section{Materials and Methods}

\subsection{Clay mineral}

Wyoming sodium smectite (Mt), obtained from the Source Clay Minerals Repositery, University of Missouri (Columbia, MO) was used in this study as a starting material. The Mt clay was fractioned to $<2 \mu \mathrm{m}$ by gravity sedimentation, purified and Na exchanged by well-established procedures[29, 30].The resulting sodium exchanged Mt clay mineral shows a cation exchange capacity (CEC) of 82 meq per $100 \mathrm{~g}$ clay in good agreement with previous observations [29, 30]. The measure of the CEC was carried out following a well-known and established procedure [31]. Briefly, a solution of $0.01 \mathrm{M} \mathrm{Cu}(\mathrm{II})-$ triensulphate has been prepared from $1.596 \mathrm{~g}$ of copper sulphate and $1.508 \mathrm{~g}$ of triethylenetetramine. 100 +/- $25 \mathrm{mg}$ of clay sample were added to $25 \mathrm{~mL}$ of distilled water and to $8 \mathrm{~mL}$ of $\mathrm{Cu}$ (II)triensulphate. The solution has been dispersed using tube roller overnight and was further centrifuged (10 minutes at $6000 \mathrm{rpm}$ ) to removed $3 \mathrm{~mL}$ of the supernatant. Measurement of $\left[\mathrm{Cu}^{2+}\right]$ was performed using Atomic Absorption Spectroscopy (AAS) with 2-8100 Polarized Zeeman Hitachi instrumentation and colorimetric techniques. The CEC was then calculated with reference to the dry clay weight, to the water content and to the amount of captured $\mathrm{Cu}^{2+}$ ions deduced from AAS measurements.

\subsection{Experimental techniques}

The concentration of organic carbon in solution was measured using an elemental analyzer (Shimadzu TOC 5050 /SSM 5000-A). Moreover, elemental analyses (Carbon, Nitrogen) on powder form samples were performed by using a Thermo Scientific Flash 2000 organic analyzer.

Fourier transform infrared (FTIR) measurements in the range 650-4000 $\mathrm{cm}^{-1}$, were recorded using a Thermo Nicolet 6700 FT spectrometer equipped with a Deuterated Triglycine Sulfate (DTGS) detector and a Nicolet Continu $\mu \mathrm{m}$ microscope. The powder samples were spread over a $\mathrm{NaCl}$ window of the microscope. The analyzed sample area was a square of side $100 \mu \mathrm{m}$ chosen under the microscope $15 \mathrm{X}$ 
Infinity Reflechromat objective. The analyses were performed in transmission mode and each spectrum was the average of 256 scans collected at $2 \mathrm{~cm}^{-1}$ resolution.

The $\mathrm{d}_{001}$ spacing's of the starting Mt clay mineral and after being in contact with organic pollutants were determined by the first $00 \mathrm{l}$ reflection from the X-rays patterns which were recorded in a conventional $\theta-\theta$ Bragg-Brentano configuration by using a Thermo Electron ARL'XTRA diffractometer equipped with a $\mathrm{Cu}$ anode $\left(\mathrm{CuK}_{\mathrm{al}, 2}=1.5418 \AA\right)$ coupled with a $\mathrm{Si}(\mathrm{Li})$ solid detector. The diffractograms on dry samples $\left(100^{\circ} \mathrm{C}\right.$ for 24 hours) were performed between 2 and $64^{\circ}(2 \theta)$ with an angular and time steps of $0.04^{\circ}$ and 10 s respectively.

\subsection{Sorption of the micro-emerging pollutants}

Doxepin and tramadol, purchased from Sigma-Aldrich Chemical, and assumed to have a purity>98\% were used without any further purification. Both doxepin and tramadol display tertiary amine moiety while showing further structural differences with a tricyclic structure for doxepin conferring a more pronounced hydrophobic character in contrast to tramadol that exhibits an alcohol group (Figure 1). Since tramadol and doxepin have an aqueous solubility better than 10 g.L $\mathrm{L}^{-1}$ (hydro chloride form) allowing a study of their adsorption on a wide range of concentration onto clay mineral, batch sorption isotherms were conducted in duplicate using at least 10 initial aqueous concentrations ranging from 20 mg. $\mathrm{L}^{-1}$ to $10 \mathrm{~g} . \mathrm{L}^{-1}$. The prepared aqueous solutions of the organic micro-pollutants were added to $\mathrm{Mt}$ clay mineral sorbent contained in $50 \mathrm{~mL}$ centrifuge tubes. Samples were shaken on a rotary shaker at $250 \mathrm{rpm}$ for $16 \mathrm{~h}$ in order to achieve the equilibrium of adsorption determined with preliminary tests, and then centrifuged at $5500 \mathrm{rpm}$ for $30 \mathrm{~min}$. The kinetics of the adsorption (not shown here) followed a similar trend for both PPs. Indeed, the adsorbed PP amount increased as initial PP concentration in solution increased while these values tend to be constant after a very short time. Nevertheless, the increase of the adsorbed PP amount did not evolve proportionally resulting to a competition between the diffusive contribution of the mass transfer process and electrostatic repulsion between PPs molecules. We assumed that an equilibrium state was reached after 150 to 300 minutes for both PPs as previous authors observed and by performing the adsorption experiments under the same conditions of 16 hours 


\section{ACCEPTED MANUSCRIPT}

of contact time, we were in the adsorption equilibrium which allowed us to determine the adsorption isotherms which are fundamental for the description of the behavior between adsorbate and adsorbent. Both supernatants and Mt sorbents after 16 hours contact with the PPs were removed and analyzed through dissolved organic carbon technique and elemental analyzer. The amount of adsorbed organic contaminants was determined through the results obtained from the Flash organic analyzer. Moreover, the analyses of the supernatants of the PPs solutions through dissolved organic carbon allowed us to determine the adsorption isotherms for both tramadol and doxepin emerging micro-pollutants on the clay mineral. Before their XRD and FTIR characterizations, the entire resulting layered composites (MtPPs) after adsorption of PPs were dried at $100^{\circ} \mathrm{C}$ for 48 hours excluding any hydration or adsorption of water of the samples. The effect of temperature through thermogravimetric analysis experiments (not shown) on the stability of the samples was checked and we assumed that in this temperature range, no adsorbed or intercalated organic species were degraded but only water was evaporated or eliminated allowing one to work on dehydrated samples for XRD and FTIR experiments.

Figure 1: Chemical structures of (a) Doxepin and (b) Tramadol.

(a)

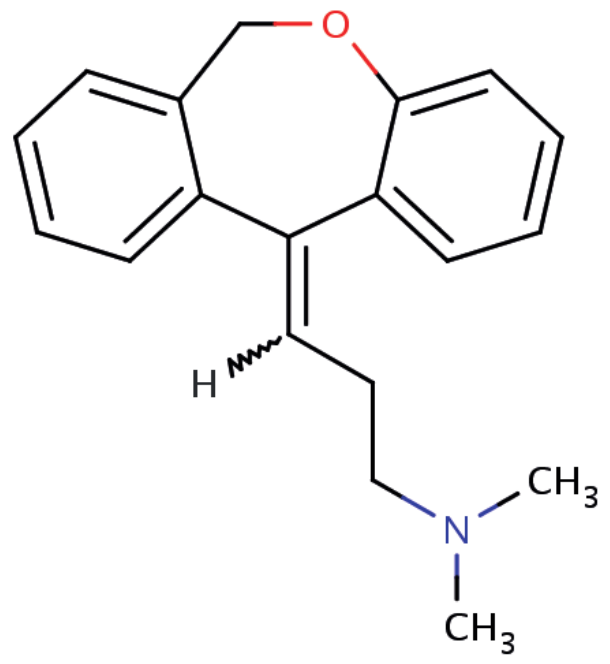

(b)

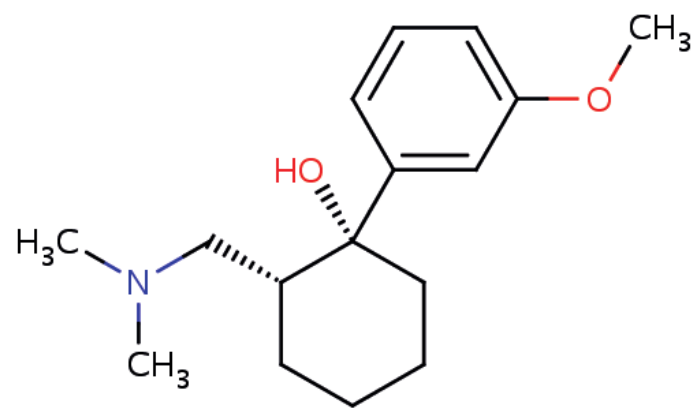




\section{Results and Discussion}

\subsection{Adsorption mechanisms of PPs on the geo-adsorbent}

The adsorption isotherms stress out the excellent affinity of studied PPs with the swelling clay. Indeed, the adsorption isotherms show two distinct regimes with one displaying a gradual growth of the adsorbed PPs amounts with equilibrium PPs concentration whereas the second one points out a steady state at high concentration (Figure 2). Values of $\mathrm{pH}$ of PP solutions after being in contact with clay dispersions were balanced to $\approx 7-7.5$. For such $\mathrm{pH}$, below the $\mathrm{pKa}$ values of both tramadol (13.8 and 9.23) and doxepin (9.76) respectively, PPs are positively charged. Moreover, at this $\mathrm{pH}$ value mainly controlled or adjusted by the clay dispersion, which acts as a buffer solution at a pH of 6-7 (higher than the $\mathrm{pH}_{\mathrm{PZC}}$ of the $\mathrm{Mt}$ ), the clay mineral surface is assumed to be negatively charged and thus can exchanged $\mathrm{Na}^{+}$cations and interact with the positively charged PP molecules through electrostatic interaction. Thus adsorbed PPs amounts onto Mt linearly increase with the PPs concentration in solution due to a possible cation exchange with compensating $\mathrm{Na}^{+}$of the clay mineral in stoichiometric proportions. Whereas chemical analyses of the PP solutions before being in contact with clay dispersions did not show any presence of $\mathrm{Na}^{+}$cations (or just in trace), the analyses of PP supernatants through atomic absorption technique highlighted the expelling of $\mathrm{Na}^{+}$at a concentration reaching the CEC (82 meq / $100 \mathrm{~g}$ of clay) that confirm a cation exchange as the way for the adsorption of PP onto clay mineral.

The fit of the resulting adsorption isotherms by using Langmuir, Freundlich and DubininRadushkevich (DR) equation models drive to numerous thermodynamic parameters allowing one to precisely quantify the affinity of both PPs with the clay mineral. Briefly, Langmuir model is expressed by the following equation [32]:

$$
q_{e}=\frac{q_{\max } K_{L} C_{e}}{1+K_{L} C_{e}}
$$




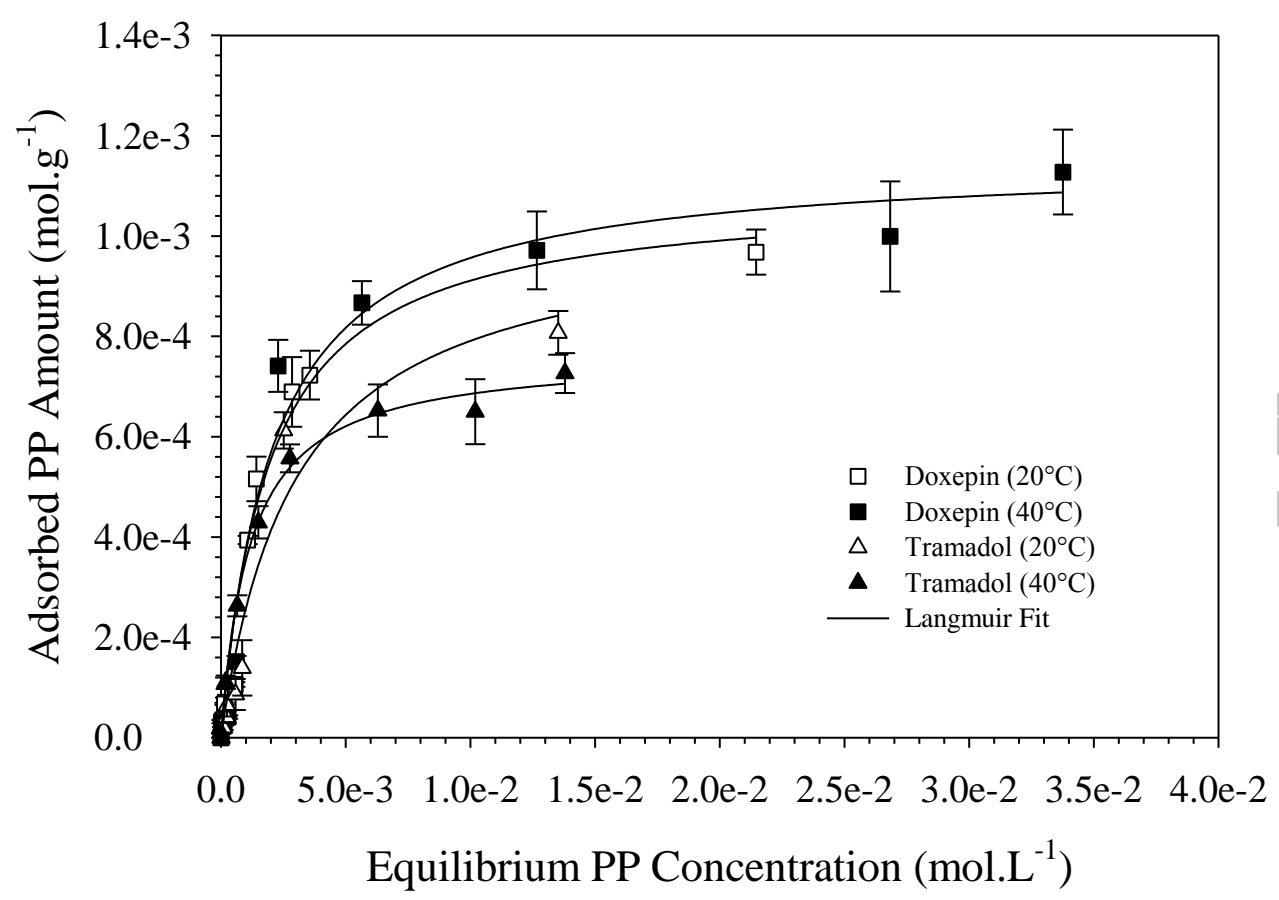

Figure 2: Adsorption isotherms of Doxepin (black and white squares) and Tramadol (black and white triangles) onto a Na exchanged smectite for the temperatures of 20 and $40^{\circ} \mathrm{C}$. The solid line represents Langmuir model fit.

where $\mathrm{q}_{\mathrm{e}}$ is the equilibrium PP amount adsorbed on Mt sorbent (mol.g-1), $C_{e}$ the equilibrium PP concentration in the supernatant $\left(\mathrm{mol} . \mathrm{L}^{-1}\right), q_{\max }$ the maximum adsorption capacity of the sorbents $\left(\mathrm{mol} . \mathrm{g}^{-}\right.$ $\left.{ }^{1}\right)$ and $K_{L}$ is the Langmuir adsorption constant $\left(\mathrm{L}_{\mathrm{mol}}{ }^{-1}\right)$ which is related to the free energy $\left(\Delta \mathrm{G}^{\circ}\right)$ of adsorption by the relation (2):

$$
\Delta G^{\circ}=-R T \ln K_{\mathrm{L}}
$$

The linear Freundlich model equation is written as [32-34]:

$$
\ln q_{e}=\ln K_{F}+\frac{1}{n} \ln C_{e}
$$

where $K_{F}\left(\mathrm{~L} . \mathrm{g}^{-1}\right)$ and $\mathrm{n}$ are the Freundlich constants indicating the extent of the adsorption and the degree of nonlinearity between PPs and the Mt geosorbent respectively. The linear expression of the DR model used to adjust our experimental data is expressed as:

$$
\ln q_{e}=\ln q_{m}+\beta \varepsilon^{2}
$$




\section{ACCEPTED MANUSCRIPT}

where $\varepsilon$ corresponds to the Polanyi potential of which relation including $C_{e}$ the equilibrium $\mathrm{PP}$ concentration could be found elsewhere. The constant $\beta$ corresponds to the activity coefficient associated to the mean free energy $E\left(\mathrm{~kJ} \cdot \mathrm{mol}^{-1}\right)$ by the equation (5) [32-34]:

$$
E=(2 \beta)^{-1 / 2}
$$

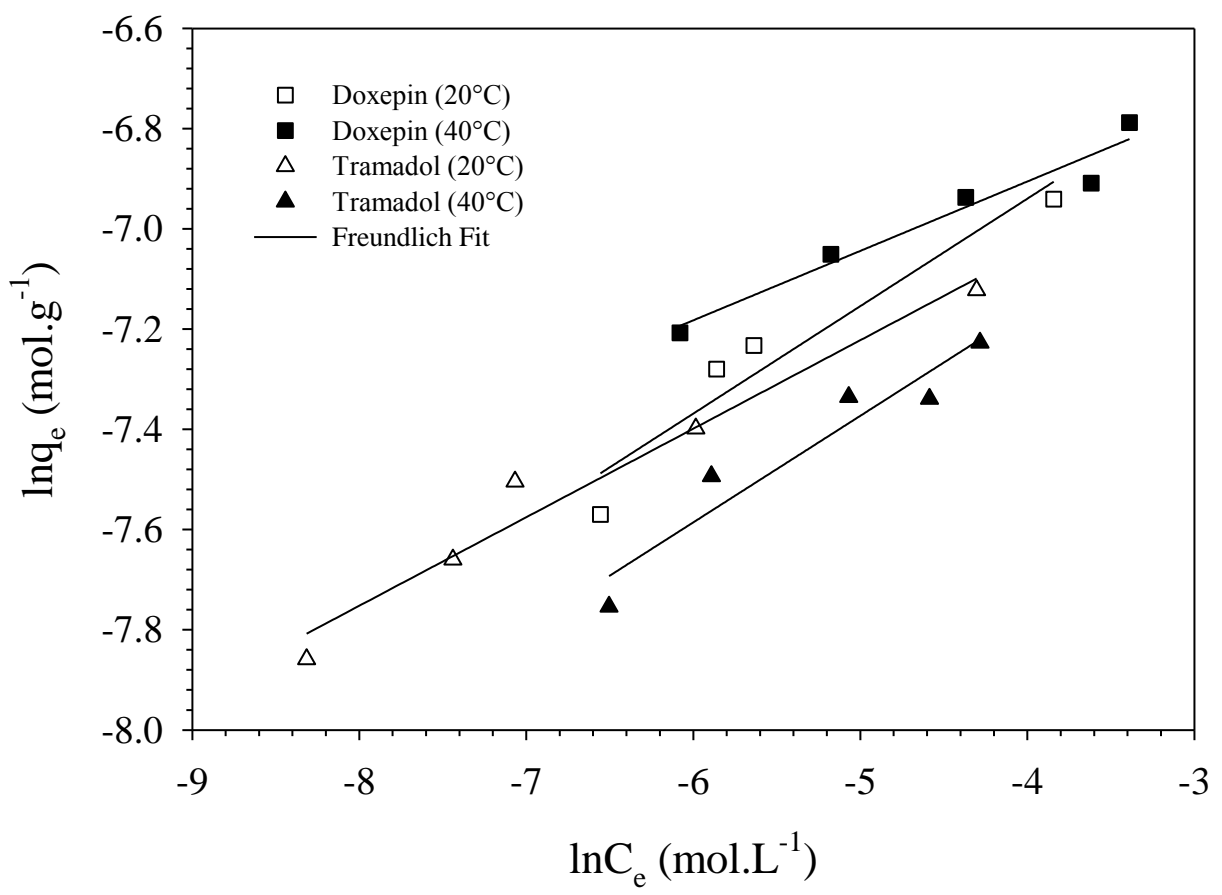

Figure 3: Adsorption isotherms of Doxepin (black and white squares) and Tramadol (black and white triangles) onto a Na exchanged smectite for the temperatures of 20 and $40^{\circ} \mathrm{C}$. The solid line represents Freundlich model fit.

This later parameter gives information whether the adsorption mechanism involves a cation exchange or physical adsorption. Indeed, if the magnitude of $E$ is below $8 \mathrm{~kJ} \mathrm{~mol}^{-1}$, physisorption is envisaged, while for $E>8 \mathrm{~kJ} \mathrm{~mol}^{-1}$ the adsorption process follows an ion exchange[32-34]. The whole adsorption parameters derived from and quality of the fitting procedure $\left(r^{2}\right)$ are listed in Table 1 . Moreover, since experimental errors flattened out when using log scale and thus were not shown (Figures 3-4), we used an error function $\left(F_{\text {error }}\right)$ in order to evaluate which equation models was best suited to describe these processes. A lower result from the error function indicated a smaller difference between adsorption capacity calculated by the model $\left(q_{\text {cal }}\right)$ and the experimental $\left(q_{\text {exp }}\right) . F_{\text {error }}$ can be expressed according to the following equation (6) [35]: 


$$
F_{\text {error }}=\sum_{i}^{P}\left(\frac{q_{i c a l}-q_{i \exp }}{q_{\text {iexp }}}\right)^{2}
$$

Where $q_{i \text { cal }}$ is a value of $q$ predicted by the fitted model; $q_{i} \exp$ is a value of $q$ measured experimentally; $i$ indicates the values of the initial PP concentration of the experiments; and $P$ is the number of experiments performed. The error function values for the entire isotherms are added in the Table 1.

Langmuir model is based on the assumption of monolayer adsorption on a structurally homogenous adsorbent, where all sorption sites are identical and energy equivalent whereas the empirical Freundlich equation is applicable to adsorption on heterogeneous surfaces, where the interaction between the adsorbed molecules is not limited to the formation of a monolayer. Finally, Dubinin-Radushkevich equation isotherm represents a more general model for adsorption, since it assumes a heterogeneous surface and a variability for the adsorption potential and was applied successfully for fitting the adsorption of organic species onto Mt. Here, the PPs adsorption isotherms are properly fitted by the three equation models used as $\mathrm{r}^{2}$ values show with a magnitude comprised between 0.96 and 0.99 and $F_{\text {error }}$ values are between 0.0010 and 0.130 (Table 1). Based on $\mathrm{r}^{2}$ values, experimental data seem to be better adjusted to the Langmuir model, however its function errors are higher than 0.1 and to those for both Freundlich and DR equations, which spread out from 0.001 to 0.004 . Although Langmuir equation properly fitted experimental data, the two latter equations appear to be more suitable for modeling the adsorption of PPs onto the clay mineral surface (Figures 2-4). Indeed, clay mineral shows a heterogeneous surface leading to a distribution of several adsorption sites that are taken into account in both Freundlich and DR equation models.

Nevertheless, the quality of the fit obtained by using a Langmuir equation is far enough to work on its parameters. The PP adsorbed amount $q_{\max }$, determined through Langmuir model, reach $0.8 \times 10^{-3}$ and $10^{-3}$ mol.g ${ }^{-1}$ for tramadol and doxepin respectively, which match that of the CEC $\left(8 \times 10^{-4} \mathrm{~mol} . \mathrm{g}^{-1}\right)$. Indeed, since PP molecules are positively charged once $\mathrm{pH}<\mathrm{pKa}$, the adsorption results to a cation exchange that expelled $\mathrm{Na}^{+}$cations in stoichiometric proportions as the chemical analyses showed. If, in the case of tramadol cation exchange was revealed to be the only vector for the adsorption[21], for doxepin the scenario involves another binding mechanisms. Indeed, beyond 1CEC where the entire anionic clay 


\section{ACCEPTED MANUSCRIPT}

mineral sites are supposed to be neutralized, $q_{\max }$ for doxepin exceeds $25 \%$ more than the CEC, suggesting a second process allowing the adsorption of additional molecules interacting to each other through weak molecular (hydrophobic, Van der Waals) interactions as surfactant molecules show for the preparation of organoclay composite material $[16,18,19]$. Nevertheless, DR model stresses out with $E>8 \mathrm{~kJ} \cdot \mathrm{mol}^{-1}$ (Table 1) in the studied $\mathrm{pH}$ range, cation exchange mainly ensures the adsorption of PPs, involving strong electrostatic interactions with the clay surface giving a certain stability of the resulting composite materials as well as a credit to use smectite as geosorbent for the adsorption of PPs [33, 34].

Prediction of the efficiency of the adsorption and the magnitude of the parameters derived from the fitting procedure by using Langmuir, Freundlich and DR equation models depend on numerous parameters such as the temperature, ionic strength, $\mathrm{pH}$, and both the chemical nature and molecular size of the organic cations. The effect of $\mathrm{pH}$ modifies both the density of charge of the clay surface and the chemical form of the organic compounds. Here, $\mathrm{pH}<\mathrm{pKa}$ of PPs where both tramadol and doxepin were in a cationic form leading to a thermodynamically spontaneous (with $\Delta \mathrm{G}^{\circ}<15 \mathrm{~kJ} . \mathrm{mol}^{-1}$ ) and favorable adsorption at both the temperature of 20 and $40^{\circ} \mathrm{C}$. The Freundlich constants $\mathrm{K}_{\mathrm{F}}$ and the coefficient of non-linearity $n>1$ as well as the derived $\Delta \mathrm{G}^{\circ}$ values obviously point out the better affinity of the doxepin $\left(\mathrm{K}_{\mathrm{F}} \approx 2.03 \times 10^{-3} \mathrm{~L}^{-1} \mathrm{~g}^{-1}\right)$ than that of tramadol to the clay mineral (Table 1). In contrast to doxepin that exclusively contributes to $R-N\left(\mathrm{CH}_{3}\right)_{2}^{+}$with $\mathrm{R}$ corresponding to the alkyl group) organic cation for a $\mathrm{pH}<\mathrm{pKa}$, tramadol exhibits a more complex behavior (due to its double $\mathrm{pKa}$ ) with its dissociation into both $\mathrm{R}-\mathrm{O}^{-}$and $\mathrm{R}-\mathrm{N}\left(\mathrm{CH}_{3}\right)_{2}^{+}$ionic species which limits the generation of organic cations and as a result the spontaneity of the adsorption onto the geo-sorbent [21]. 


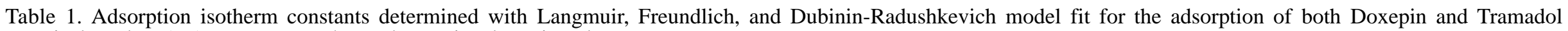
pharmaceutical product (PP) onto a Na exchanged smectite clay mineral.

\begin{tabular}{|c|c|c|c|c|c|c|c|c|c|c|c|c|c|c|}
\hline \multirow[t]{2}{*}{$\mathrm{PP}$} & \multirow{2}{*}{$\begin{array}{c}\mathrm{T} \\
\left({ }^{\circ} \mathrm{C}\right)\end{array}$} & \multicolumn{5}{|l|}{ Langmuir } & \multicolumn{4}{|l|}{ Freundlich } & \multicolumn{4}{|c|}{ Dubinin-Radushkevich (D-R) } \\
\hline & & $\underset{\left(\mathrm{mol}_{\max } \mathrm{g}^{-1}\right)}{\mathrm{q}}$ & $\begin{array}{c}\mathrm{K}_{\mathrm{L}} \\
\left(\mathrm{L} \cdot \mathrm{mol}^{-1}\right)\end{array}$ & $\begin{array}{c}\Delta \mathrm{G}^{\circ} \\
\left(\mathrm{kJ} \cdot \mathrm{mol}^{-1}\right)\end{array}$ & $r^{2}$ & $F_{\text {error }}$ & $\begin{array}{c}\mathrm{K}_{\mathrm{F}} \\
\left(\mathrm{L} \cdot \mathrm{g}^{-1}\right)\end{array}$ & $\mathrm{n}$ & $r^{2}$ & $F_{\text {error }}$ & $\underset{\left(\mathrm{mol} \cdot \mathrm{g}^{-1}\right)}{\mathrm{q}_{\mathrm{m}}}$ & $\begin{array}{c}\mathrm{E} \\
\left(\mathrm{kJ} \cdot \mathrm{mol}^{-1}\right)\end{array}$ & $r^{2}$ & $F_{\text {error }}$ \\
\hline \multirow[b]{2}{*}{ Doxepin } & $20^{\circ} \mathrm{C}$ & $10^{-3}$ & 550 & -16.38 & 0.987 & 0.076 & $2.28 \times 10^{-3}$ & 4.67 & 0.974 & 0.0012 & $2.3 \times 10^{-3}$ & 10.833 & 0.974 & 0.0024 \\
\hline & $40^{\circ} \mathrm{C}$ & $10^{-3}$ & 460 & -15.15 & 0.988 & 0.089 & $1.74 \times 10^{-3}$ & 7.25 & 0.962 & 0.0026 & $1.76 \times 10^{-3}$ & 8.717 & 0.963 & 0.0021 \\
\hline \multirow{2}{*}{ Tramadol } & $20^{\circ} \mathrm{C}$ & $0.8 \times 10^{-3}$ & 1000 & -17.27 & 0.957 & 0.130 & $1.76 \times 10^{-3}$ & 5.77 & 0.953 & 0.0067 & $1.77 \times 10^{-3}$ & 6.826 & 0.954 & 0.0052 \\
\hline & $40^{\circ} \mathrm{C}$ & $7.65 \times 10^{-4}$ & 350 & -14.44 & 0.998 & 0.083 & $1.81 \times 10^{-3}$ & 4.69 & 0.983 & 0.0034 & $1.83 \times 10^{-3}$ & 8.763 & 0.967 & 0.0035 \\
\hline
\end{tabular}

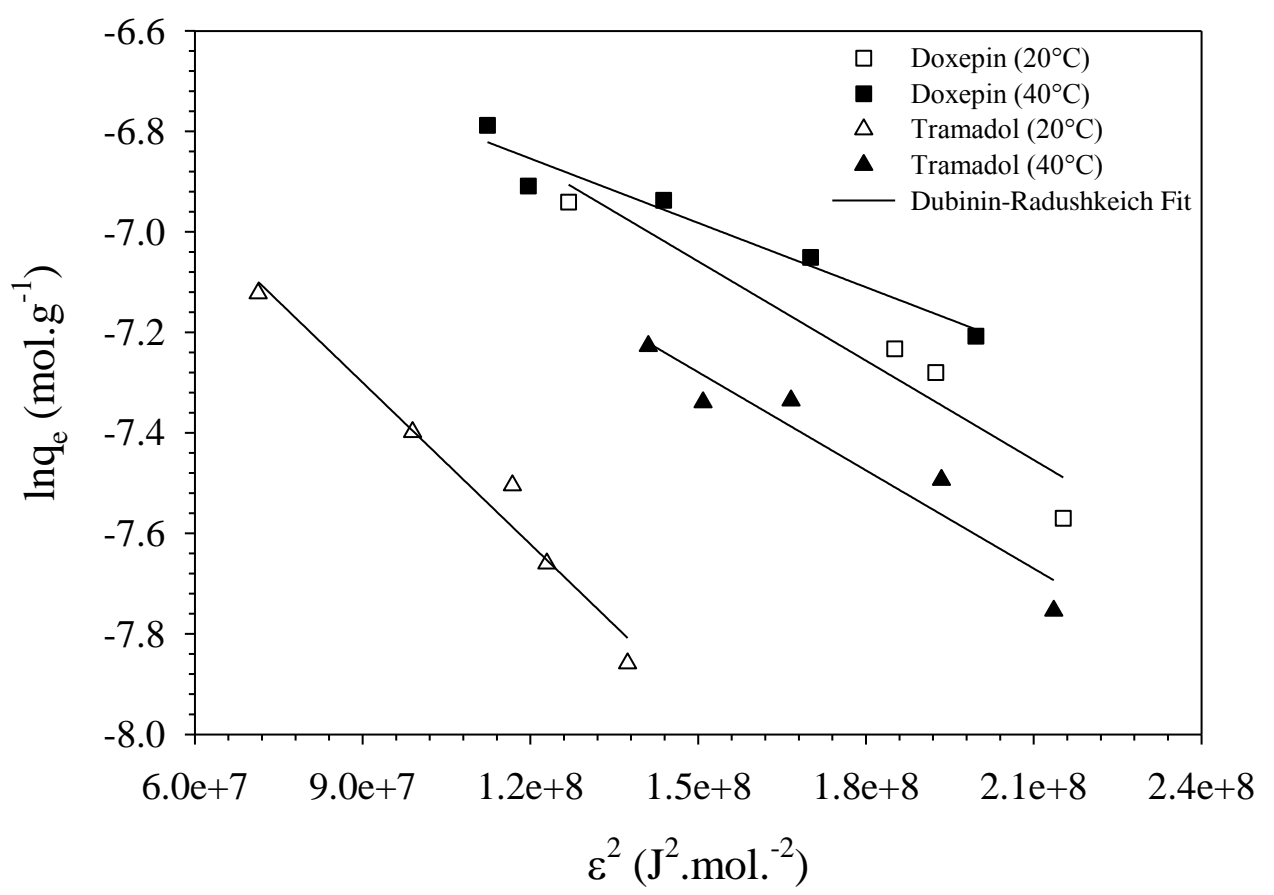

Figure 4: Adsorption isotherms of Doxepin (black and white squares) and Tramadol (black and white triangles) onto a Na exchanged smectite for the temperatures of 20 and $40^{\circ} \mathrm{C}$. The solid line represents DR model fit. 
If the spontaneity of the adsorption of PPs onto clay mineral may be related to the acidic character (or the ability of the PPs to generate organic cations), the amount of the adsorbed PPs results to the adsorption mechanisms between PPs and the clay surface on one hand, and between PPs molecules on second hand as organoclay preparation occurs $[16,18,19,30]$. Indeed, the intercalation of long alkyl tail cationic surfactants such as quaternary ammonium compounds for the preparation of the well-known organoclays takes two steps: (i) a total adsorption through cation exchange until 1CEC; and (ii) the packing of further surfactants due to hydrophobic interaction of the hydrocarbon chains. Here, the tricyclic antidepressant doxepin displays a hydrophobic group allowing the adsorption of additional molecules (about $25 \%$ more that of the CEC) through $\pi-\pi$ or/and hydrophobic weak molecular interactions.

If the effect of $\mathrm{pH}$ and even the chemical context of PPs reasonably could be apprehended, temperature may drive to antagonist situations. Indeed, while temperature increases mobility of organic (i.e. reduction of mean free path) compounds making easier the adsorption or contact with a surface, it also reduces the energy of activation of numerous processes. Nevertheless, several experimental studies on the adsorption of different kind of pollutants onto clay minerals or soils pointed out an increase of temperature reduces the percentage of adsorption $[33,34]$. Here, since the sorption isotherms follow the same trend, temperature appears to play a minor role. However, the Langmuir derived constants with $\Delta \mathrm{G}^{\circ}=-16.38$, $15.15 \mathrm{~kJ} \cdot \mathrm{mol}^{-1}$ for doxepin and -17.27 and $-14.44 \mathrm{~kJ}^{\mathrm{mol}}{ }^{-1}$ for tramadol to temperatures of 20 and $40^{\circ} \mathrm{C}$ respectively emphasize the better affinity of the PPs to clay surface at low temperature which was also observed by other researchers that employed clay mineral for removal both inorganic and organic pollutants $[33,34]$. Temperature favors an adsorption process by increasing a diffusive contribution of the mass transfer process while it reduces electrostatic attractions between PPs and the clay mineral surface. Nevertheless, here the balance between these opposite effects results to a decrease of the driving force with the increase of the temperature. 


\subsection{Structure and conformation of the adsorbed PPS}

The resulting adsorption isotherms and derivative parameters obtained through the fitting procedure attest to a cation exchange as the main adsorption process leading with the release of $\mathrm{Na}^{+}$cations to the logical intercalation of PPs within the interlayer space of smectite. If the maximum adsorbed amount that reaches the CEC leaves no doubt of the possible arrangement for tramadol in lateral monolayer [21], the Doxepin-Mt composite materials require to be characterized by X-Ray diffraction for a clear establishment of the organization of the doxepin within the interlayer space.

X-Ray diffraction (XRD) represents an indispensable technique for the determination of the structural changes in layered materials. Indeed, a PP intercalation can be probed by focusing on the angular position of the first 001 reflection, while XRD patterns at wide angles give critical information about a possible crystallization of PPs on the phyllosilicate sheets. The hydration of clay mineral leads to intercalation of water layers that expand the interlayer space at several discrete values at 9.6,12 and 15.5 $\AA$ for a dehydrated, monolayer hydrated and bilayer hydrated state $\mathrm{Na}-\mathrm{Mt}$ [36]. In order to avoid any contribution of the hydration state of the resulting layered composite materials on the possible angular shift of the $00 l$ reflection, the entire samples were dehydrated in a oven at $100^{\circ} \mathrm{C}$ for $48 \mathrm{~h}$.

The structural changes of the entire layered composite samples with the increase of the PP concentration follow the same trend as that which is represented in Figure 5of doxepin-Mt samples at $40^{\circ} \mathrm{C}$. Although the signal is masked by the strong scattering of the clay platelets at low angular value, diffractograms show several diffraction peaks located between 4.6 to $10^{\circ}$ (20) related to the $00 l$ reflection. Moreover to shift to lower angular value underlining the proper intercalation organic compounds, it is interesting to remark as the PP density increases within the interlayer space, the $00 l$ reflections are refined. The introduction of PPs within the interlayer space screen up the electrostatic repulsion of the phyllosilicate layers and thus helps to stabilize their arrangements generating a coherent unit at a larger scale $[18,30,36]$. 


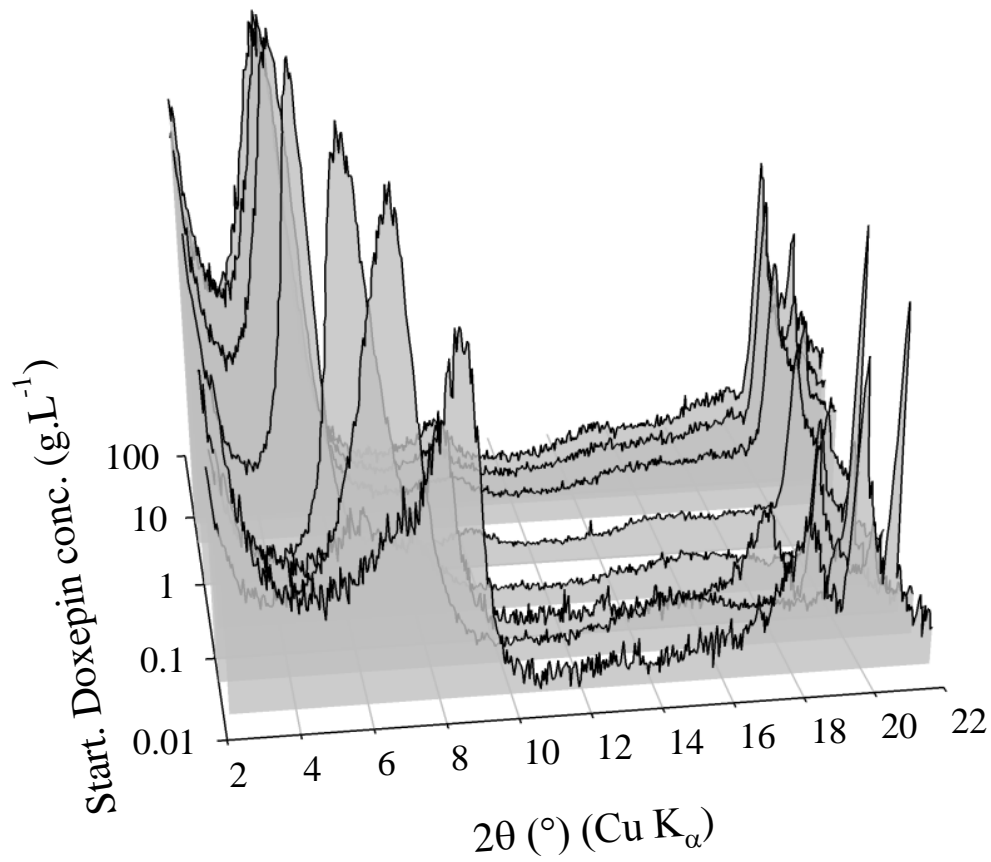

Figure 5: 3D evolution of the $\mathrm{X}$-ray diffraction patterns of the dehydrated Doxepin-Mt layered composite materials as a function of the starting PP concentration in solution for the temperature of $40^{\circ} \mathrm{C}$ (selected series but we assumed to get a similar evolution for the entire PP-Mt layered composite materials).

The insertion of PPs in the interlayer space expands the distance between the layers, giving a $\mathrm{d}_{001}$ spacing of which evolution follows the same trend as the adsorption isotherms. Below a starting concentration of $1 \mathrm{CEC}$ where a cation exchange is not total, due to the flexibility of the smectite sheets the interbasal distance gradually increases from 9.6 (for dehydrated clay mineral) to $14.5 \AA$ or more (for a monolayer of PP) (Figure 6). In this concentration regime, only part of $\mathrm{Na}^{+}$is exchanged by organic cations (where the adsorption is total) which leads to two possibilities for the configuration of the interlayer space: an interstratified situation with separate organic and inorganic interlayers with only $\mathrm{Na}^{+}$cations or layers where both $\mathrm{Na}^{+}$and PP cations coexist and whose basal spacing is driven by an uniform PP monolayer coverage. However, here the absence of any $00 \mathrm{l}$ reflection corresponding to an inorganic raw smectite (Figure 5) and the existence of only one broad peak which highlights the structure of the layered PP-Mt composite material indicate that both organic and inorganic cations coexist in 
the same interlayer space and leads to a distribution for the $d_{001}$ spacing. For the high concentration regime ( $>$ 1CEC), where the entire compensating $\mathrm{Na}^{+}$cations are substituted to the benefit of PPs, The insertion of tramadol and doxepin gives a $d_{001}$ spacing of 16.3 and 18.6 $\AA$. This corresponds to an intersheet separation of 6.6 and $\approx 9 \AA$ that matches the thickness of both the tramadol and doxepin molecules, which must adopt a lateral monolayer organization between the clay surfaces [21]. Even in the regime where the adsorption isotherms corresponds to $n_{i} \neq n_{a d s}$, the $d_{001}$ spacing remains at the same values of 16.3 and $18.6 \AA$ for tramadol and doxepin respectively (Figure 6) underlining PP cations keep a similar arrangement within the interlayer space with a high intercalation level unto the accessible sites.

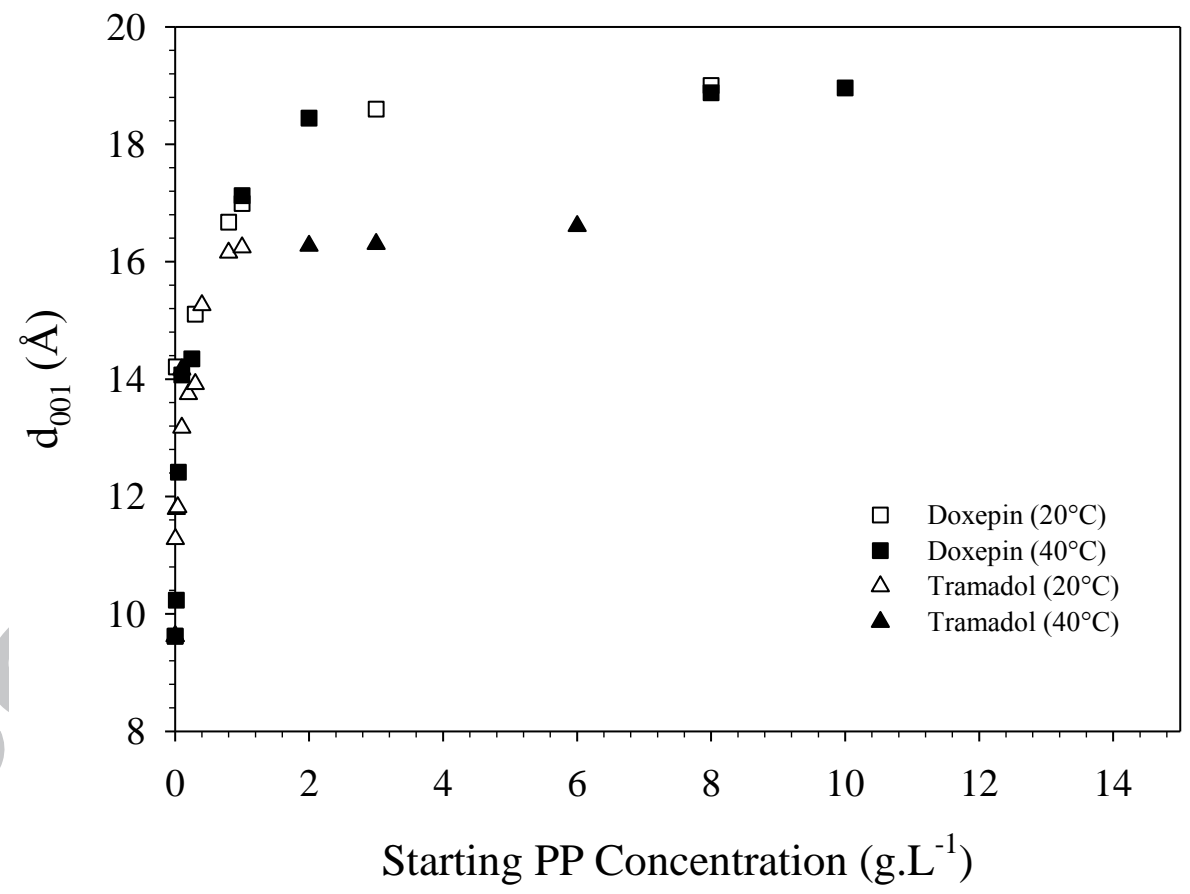

Figure 6: Evolution of the $\mathrm{d}_{001}$ basal spacing determined by the $00 \mathrm{l}$ reflection of the silicates sheets obtained from X-ray diffraction patterns of PP-Mt layered materials after their impregnation in PP solutions at several concentrations for $48 \mathrm{~h}$ (Doxepin in white and black squares for the temperatures of 20 and $40^{\circ} \mathrm{C}$ respectively and Tramadol in white and black squares for the temperatures of 20 and $40^{\circ} \mathrm{C}$ respectively).

Moreover, another piece of important information derived from X-ray diffraction patterns of the PP-Mt samples (not shown) was the absence of reflection peaks of both tramadol and doxepin in the $2 \theta$ region $24-64^{\circ}$. PP are well known product to form aggregates onto surfaces following different pathways which change the conformation of the PP monomers and reduce 
as well as their therapeutic actions [37]. The absence of reflection peaks of both tramadol and doxepin indicates that PP cations were mainly intercalated in a monolayer arrangement (Figure 7) within the interlayer space and did not crystallize nor were not aggregated onto the clay surface. Thus, the use of clay mineral prevents anaggregation mechanism or crystallization/nucleation of both tramadol and doxepin, and even for the latterPP molecule at low temperature where additional doxepin molecules can be packed. The confinement of PPs within the internal space onto localized adsorption sites leading to a monolayer organization without any (or few) interaction between PP molecules avoiding in this way any crystallization or aggregation.

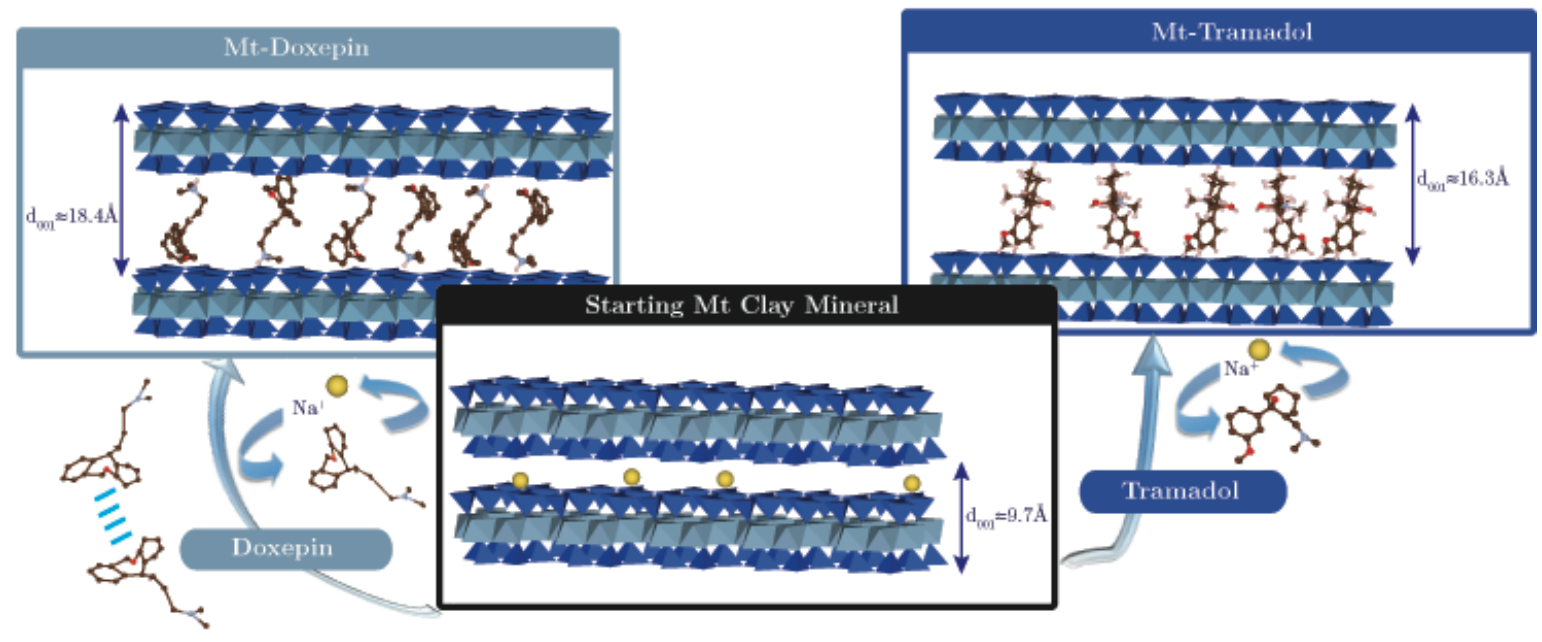

Figure 7: Possible adsorption mechanisms of both tramadol (ion exchange) and doxepin (ion exchange and weak molecular interactions) PPs onto a smectite clay mineralleading to their intercalation in a monolayer arrangement.

At such interlayer scale $(<2 \mathrm{~nm})$, the phyllosilicate layers impose several confinements effects such as finite size effects, and interaction with the surface that may affect both the structure and the dynamics of the intercalated PPs [18]. If X-ray diffraction represents a powerful tool for the determination of the structural change of the host material, it cannot provide any relevant information for the confined system. In contrast, Fourier transform infrared (FTIR) spectroscopy was successfully used for the characterization of the molecular organization and conformational change of numerous organic species adsorbed onto surface. 
Indeed, the degree of molecular order in the intercalated surfactants was determined through FTIR experiments by focusing on the frequency changes of the $\mathrm{CH}_{2}$ stretching bands of the hydrocarbon chains of the amphiphilic molecules. Although showing only three methyl groups, spectra of the confined tramadol display two intense absorption bands around 2860 and $2930 \mathrm{~cm}^{-1}$ assigned to the symmetric and asymmetric $\mathrm{CH}_{2}$ stretching bands (Figure 8) [21]. For bulk crystalline tramadol, these bands appear at 2858 and $2928 \mathrm{~cm}^{-1}$. When confined into smectite clay, the wavenumbers of both asymmetric and symmetric $\mathrm{CH}_{2}$ stretching bands of tramadol (same observations were noticed for doxepin but are not shown) shift to higher frequencies on one hand, and appear broader on the other hand. These observations that depend on the density of confined PP within the interlayer space stress out the introduction of small conformational change in the methyl groups as well as an amorphization or a structural disorder in the organization of PP cations. Such conformational changes occur not only in the peripheral groups but also in the inner part of confined PPs molecules including aromatic rings whose $\mathrm{CH}$ deformation bands show a shift in frequency and appear to be broader (Figure 9).The impact of confinement in a slit of $<2 \mathrm{~nm}$ leads to an amorphous organization where PPs display a conformational change with a disordered structure, which is far more pronounced at low concentration regime. Current solid-state nuclear magnetic resonance experiments (not shown here) explicitly confirm such conformational change for confined PPs of which dynamics appear as a glassy like state. 


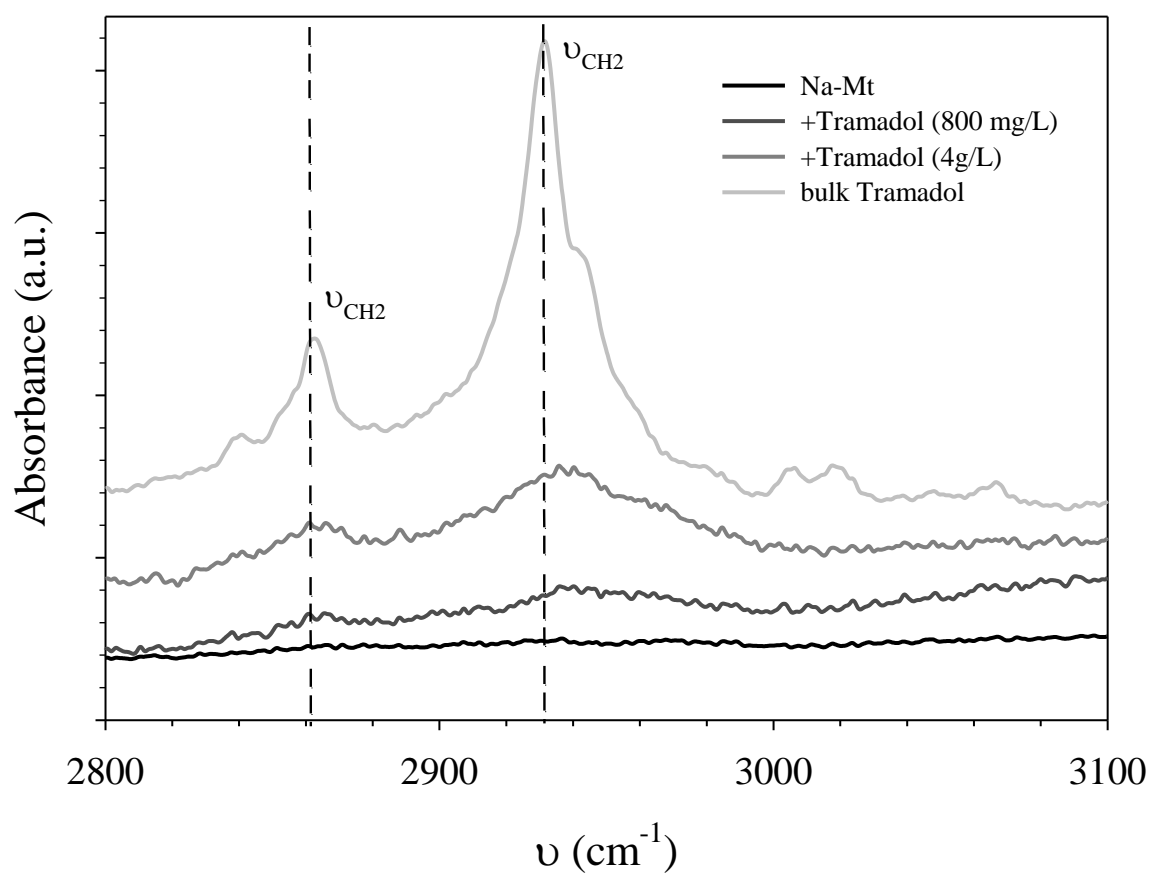

Figure 8: FTIR spectra - from bottom to top - of Na-Mt, Tramadol-Mt composite materials obtained for a starting PP concentration of $800 \mathrm{mg} / \mathrm{L}$ and $4 \mathrm{~g} / \mathrm{L}$ respectively and bulk tramadol. Spectra were normalized with respect to the $\mathrm{Si}-\mathrm{O}$ stretching band at $1100 \mathrm{~cm}^{-1}$. The confirmation of the proper tramadol adsorption onto $\mathrm{Na}-\mathrm{Mt}$ is highlighted by representative absorption bands attributed to $\mathrm{CH}$ stretching vibrations at $2850-3000 \mathrm{~cm}^{-1}$ (dashed lines) which shift to high frequency once confined within the interlayer space.

Indeed, numerous studies showed that confined systems can exhibit dynamical features which are commonly related to the phenomenology of the glass transition in terms of nonDebye character of structural relaxation $[25,28,38]$. Here, the non-aggregation of the PP molecules due to their confinement in localized adsorption sites within the interlayer space blocks the crystallization of PP, which show a tendency to supercooling and metastability [25, 28]. PPs in an amorphous state exhibit greater performances such as a better chemical reactivity and favorable dissolution properties than their crystalline analogous thermodynamically stable [23]. Nevertheless, while the preparation of amorphous PPs may be desirable, their uses in such form was rejected as a formulation strategy by pharmaceutical companies due to numerous difficulties: (i) amorphous or metastable systems are thermodynamically unstable and tend to revert to a crystalline form; (ii) physical structure if glassy materials is rather difficult to characterize; and (iii) characteristics of amorphous drugs 
have to be considered in the light of regulatory requirements [23]. Moreover to control the release of the PPs by limiting the amount of PPs for a similar therapeutic action, which was underlined by numerous studies [21, 24], the concept of drug delivery systems by using clay minerals as host biocompatible materials opens an alternative promising route to prepare amorphous systems with a potential means of considerably enhancing product performance.

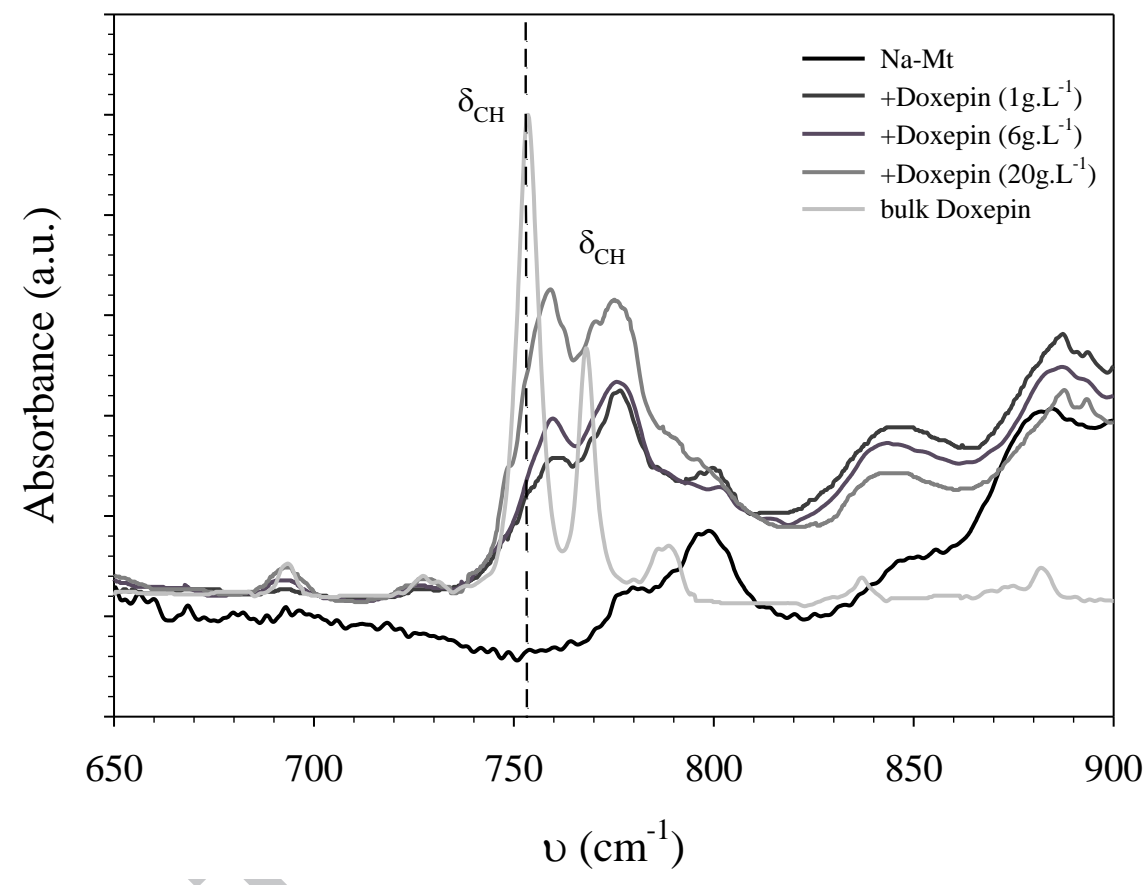

Figure 9: FTIR spectra - from bottom to top - of Na-Mt, Doxepin-Mt composite materials obtained for a starting PP concentration from 1 to $20 \mathrm{~g} / \mathrm{L}$ respectively and bulk Doxepin. Spectra were normalized with respect to the Si-O stretching band at $1100 \mathrm{~cm}^{-1}$. The confirmation of the proper tramadol adsorption onto $\mathrm{Na}-\mathrm{Mt}$ is highlighted by representative absorption bands attributed to $\mathrm{CH}$ bending vibrations (aromatic) at $750-800 \mathrm{~cm}^{-1}$ (dashed lines) which shift to high frequency once confined within the interlayer space. 


\section{Conclusion}

Clay minerals show outstanding adsorption properties for numerous organic products. The adsorption success for organic compounds on clay minerals mainly depends on the magnitude of the interactional processes that ensure both cohesion and stability in the resulting layered composite materials. For tramadol and doxepin drugs defined as emerging micro-pollutants due to their presence at significant concentration in numerous water compartments, the adsorption onto a Na-Mt smectite clay mineral is mainly driven by electrostatic interaction through a cation exchange. Thus, PPs are confined within the interlayer space of Na-Mt in a monolayer organization. In addition, the tricyclic antidepressant doxepin PP exhibits a certain ability to interact through weak molecular interaction driving to increase the adsorbed amount beyond the CEC of smectite. Nevertheless, such interactional mechanism is somehow restricted to low temperature and for organic compounds showing a sufficient hydrophobic group. The PPs intercalation in a monolayer arrangement within the interlayer space of a $\mathrm{Na}$ exchanged smectite validates the use of clay minerals as potential material for the treatment of water on one hand, and since the confinement in Mt drives to an amorphous form for the intercalated PP as biopharmaceutical applications for a controlled release of PPs on the other hand. Nevertheless, the latter possible application requires further in-vivo experiments for probing its therapeutic efficiency.

\section{Acknowledgements}

The authors would like to thank the Région Centre (Project HarPE 2012-00073536) for their financial support. 


\section{References}

[1] T. Deblonde, C. Cossu-Leguille, P. Hartemann, Emerging pollutants in wastewater: A review of the literature, International Journal of Hygiene and Environmental Health, 214 (2011) 442-448.

[2] J.B. Ellis, Pharmaceutical and personal care products (PPCPs) in urban receiving waters, Environmental Pollution, 144 (2006) 184-189.

[3] B. Halling-Sørensen, S. Nors Nielsen, P.F. Lanzky, F. Ingerslev, H.C. Holten Lützhøft, S.E. Jørgensen, Occurrence, fate and effects of pharmaceutical substances in the environment- A review, Chemosphere, 36 (1998) 357-393.

[4] J.-Q. Jiang, Z. Zhou, V.K. Sharma, Occurrence, transportation, monitoring and treatment of emerging micro-pollutants in waste water, A review from global views, Microchemical Journal, 110 (2013) 292-300.

[5] R. Loos, R. Carvalho, D.C. Antonio, S. Comero, G. Locoro, S. Tavazzi, B. Paracchini, M. Ghiani, T. Lettieri, L. Blaha, B. Jarosova, S. Voorspoels, K. Servaes, P. Haglund, J. Fick, R.H. Lindberg, D. Schwesig, B.M. Gawlik, EU-wide monitoring survey on emerging polar organic contaminants in wastewater treatment plant effluents, Water Research, 47 (2013) 6475-6487.

[6] S. Mompelat, B. Le Bot, O. Thomas, Occurrence and fate of pharmaceutical products and byproducts, from resource to drinking water, Environment International, 35 (2009) 803-814.

[7] Y. Park, G.A. Ayoko, R.L. Frost, Application of organoclays for the adsorption of recalcitrant organic molecules from aqueous media, Journal of Colloid and Interface Science, 354 (2011) 292-305.

[8] T.A. Ternes, Occurrence of drugs in German sewage treatment plants and rivers, Water Research, 32 (1998) 3245-3260.

[9] E. Vulliet, C.c. Cren-Olivé, Screening of pharmaceuticals and hormones at the regional scale, in surface and groundwaters intended to human consumption, Environmental Pollution, 159 (2011) 2929-2934.

[10] D. Hummel, D. Löffler, G. Fink, T. Ternes, Simultaneous Determination of Psychoactive Drugs and Their Metabolites in Aqueous Matrices by Liquid Chromatography Mass Spectrometry, Environ. Sci. Technol., 40 (2006) 9.

[11] P. Boffetta, Human cancer from environmental pollutants: The epidemiological evidence, Mutation Research/Genetic Toxicology and Environmental Mutagenesis, 608 (2006) 157-162.

[12] K. Stein, M. Ramil, G. Fink, M. Sander, T.A. Ternes, Analysis and Sorption of Psychoactive Drugs onto Sediment, Environ. Sci. Technol., 42 (2008) 6415-6423.

[13] M.r. Antunes, V.I. Esteves, R.g. Guégan, J.S. Crespo, A.N. Fernandes, M. Giovanela, Removal of diclofenac sodium from aqueous solution by Isabel grape bagasse, Chemical Engineering Journal, 192 (2012) 114-121.

[14] T.V. Duncan, Applications of nanotechnology in food packaging and food safety: Barrier materials, antimicrobials and sensors, Journal of Colloid and Interface Science, 363 (2011) 1-24.

[15] H. Mansouri, R.J. Carmona, A. Gomis-Berenguer, S. Souissi-Najar, A. Ouederni, C.O. Ania, Competitive adsorption of ibuprofen and amoxicillin mixtures from aqueous solution on activated carbons, Journal of Colloid and Interface Science, DOI http://dx.doi.org/10.1016/j.jcis.2014.12.020.

[16] L.B. de Paiva, A.R. Morales, F.R. Valenzuela Díaz, Organoclays: Properties, preparation and applications, Applied Clay Science, 42 (2008) 8-24.

[17] S. Cadars, R.g. Guégan, M.N. Garaga, X. Bourrat, L. Le Forestier, F. Fayon, T.V. Huynh, T. Allier, Z. Nour, D. Massiot, New Insights into the Molecular Structures, Compositions, and Cation Distributions in Synthetic and Natural Montmorillonite Clays, Chemistry of Materials, 24 (2012) 4376-4389.

[18] R. Guégan, Self-assembly of a non-ionic surfactant onto a clay mineral for the preparation of hybrid layered materials, Soft Matter, 9 (2013) 10913-10920.

[19] R. Guégan, M. Giovanela, F. Warmont, M. Motelica-Heino, Nonionic organoclay: A 'Swiss Army knife' for the adsorption of organic micro-pollutants?, Journal of Colloid and Interface Science, 437 (2015) 71-79.

[20] W. Zhang, Y. Ding, S.A. Boyd, B.J. Teppen, H. Li, Sorption and desorption of carbamazepine from water by smectite clays, Chemosphere, 81 (2010) 954-960. 
[21] Y. Chen, A. Zhou, B. Liu, J. Liang, Tramadol hydrochloride/montmorillonite composite: Preparation and controlled drug release, Applied Clay Science, 49 (2010) 108-112.

[22] R.B. Raffa, C. Wu, D.J. Stone Jr, M.R. Borenstein, E.E. Codd, T.P. Coogan, Determination of the adsorption of tramadol hydrochloride by activated charcoal in vitro and in vivo, Journal of Pharmacological and Toxicological Methods, 43 (2000) 205-210.

[23] D.Q.M. Craig, P.G. Royall, V.L. Kett, M.L. Hopton, The relevance of the amorphous state to pharmaceutical dosage forms: glassy drugs and freeze dried systems, International Journal of Pharmaceutics, 179 (1999) 179-207.

[24] V. Rives, M. del Arco, C. Mart $\downarrow \neq n$, Layered double hydroxides as drug carriers and for controlled release of non-steroidal antiinflammatory drugs (NSAIDs): A review, Journal of Controlled Release, 169 (2013) 28-39.

[25] C. Alba-Simionesco, B. Coasne, G. Dosseh, G. Dudziak, K.E. Gubbins, R. Radhakrishnan, M. Sliwinska-Bartkowiak, Effects of confinement on freezing and melting, Journal of Physics: Condensed Matter, 18 (2006) R15.

[26] S. Balme, R. Guégan, J.-M. Janot, M. Jaber, M. Lepoitevin, P. Dejardin, X. Bourrat, M. MotelicaHeino, Structure, orientation and stability of lysozyme confined in layered materials, Soft Matter, 9 (2013) 3188-3196.

[27] R. Guégan, Confinement effects on water structure in membrane lyotropic phases, Journal of Colloid and Interface Science, 358 (2011) 485-490.

[28] R. Guégan, D. Morineau, C. Alba-Simionesco, Interfacial structure of an H-bonding liquid confined into silica nanopore with surface silanols, Chemical Physics, 317 (2005) 236-244.

[29] M. Gautier, F. Muller, L. Le Forestier, J.M. Beny, R. Guegan, NH4-smectite: Characterization, hydration properties and hydro mechanical behaviour, Applied Clay Science, 49 (2010) 247-254.

[30] R. Guégan, Intercalation of a Nonionic Surfactant (C10E3) Bilayer into a Na-Montmorillonite Clay, Langmuir, 26 (2010) 19175-19180.

[31] L. Meier, G. Kahr, Determination of the Cation Exchange Capacity ( $\{\mathrm{CEC}\}$ ) of Clay Minerals Using the Complexes of Copper(II) Ion with Triethylenetetramine and Tetraethylenepentamine, Clays and Clay Minerals, 47 (1999) 386-388.

[32] M.D. LeVan, T. Vermeulen, Binary Langmuir and Freundlich isotherms for ideal adsorbed solutions, The Journal of Physical Chemistry, 85 (1981) 3247-3250.

[33] A.S. Ozcan, B. Erdem, A. Ozcan, Adsorption of Acid Blue 193 from aqueous solutions onto BTMA-bentonite, Colloids and Surfaces A: Physicochemical and Engineering Aspects, 266 (2005) 73-81.

[34] A. Sar, M. Tuzen, M. Soylak, Adsorption of $\mathrm{Pb}(\mathrm{II})$ and $\mathrm{Cr}(\mathrm{III})$ from aqueous solution on Celtek clay, Journal of Hazardous Materials, 144 (2007) 41-46.

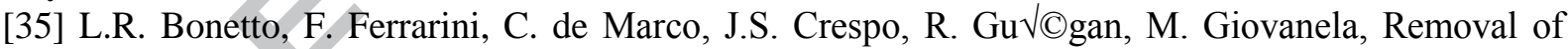
methyl violet $2 \mathrm{~B}$ dye from aqueous solution using a magnetic composite as an adsorbent, Journal of Water Process Engineering, 6 (2015) 11-20.

[36] E. Ferrage, B. Lanson, B.A. Sakharov, V.A. Drits, Investigation of smectite hydration properties by modeling experimental X-ray diffraction patterns: Part I. Montmorillonite hydration properties, American Mineralogist, 90 (2005) 1358-1374.

[37] J.S. Philo, T. Arakawa, Mechanisms of Protein Aggregation, Current Pharmaceutical Biotechnology, 10 (2009) 348-351.

[38] R. Lefort, D. Morineau, R. Guégan, A. Moréac, C. Ecolivet, M. Guendouz, Structure and relaxation processes of an anisotropic molecular fluid confined into 1D nanochannels, Philosophical Magazine, 87 (2007) 469-476. 
Graphical abstract

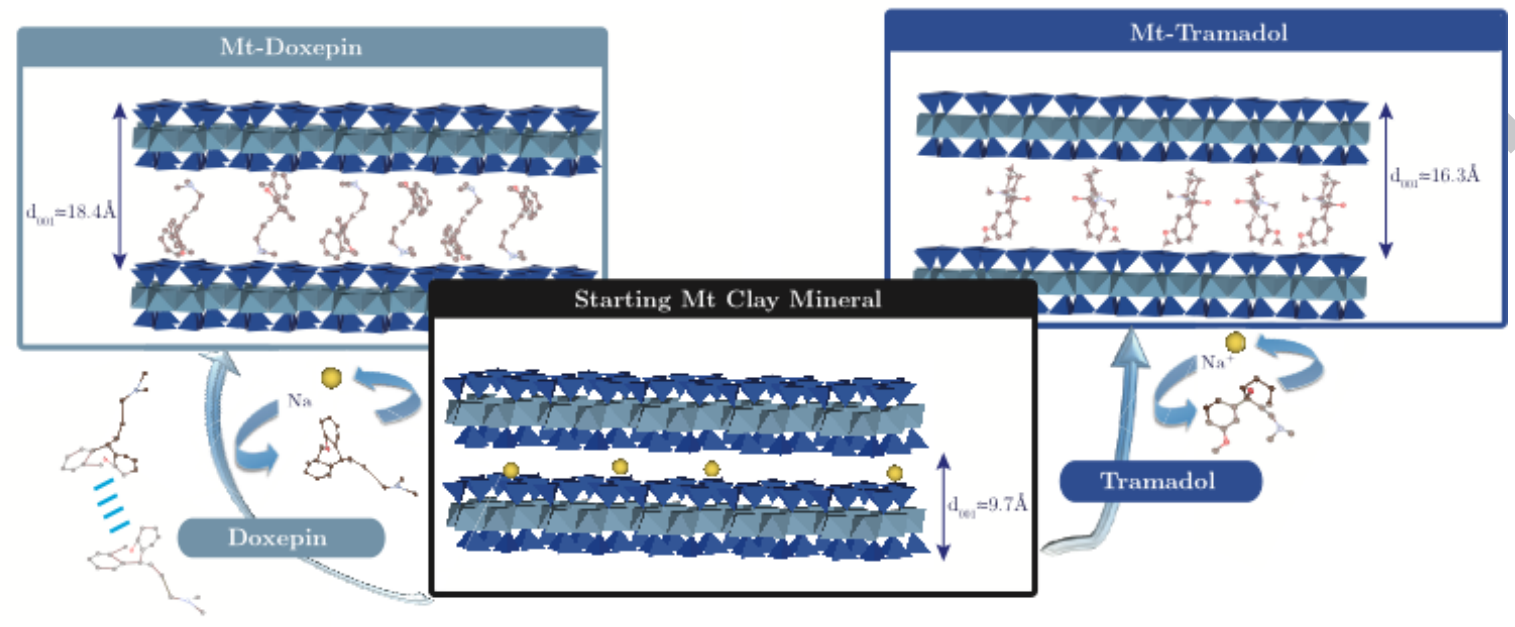

Possible adsorption mechanisms of both tramadol (ion exchange) and doxepin (ion exchange and weak molecular interactions) Pharmaceutical Products onto a smectite clay mineral leading to a monolayer arrangements for the confined PPs. 